\title{
TELEVISION
}

\section{Dover trial documentary screens}

\section{Judgment Day: Intelligent Design on Trial produced by NOVA \& Vulcan Productions for PBS \\ broadcast on 13 November on PBS}

\section{Adam Rutherford}

Conflict between religion and science has rarely been of more concern. Whereas the rhetoric of Richard Dawkins, Sam Harris and others has little measurable effect, the outcome of a juryless trial in a two-bit Pennsylvania town in 2005 had a profound impact on how science is taught throughout the United States, and beyond. The parents of 11 pupils at the only high school in Dover launched a legal challenge to prevent the teaching of intelligent design as an alternative to evolution by natural selection. There followed thefts, fires, death threats, a media sensation and a robust verdict.

Hot on the heels of several books chronicling Kitzmiller vs Dover, comes Judgment Day, a rigorous television documentary from the producers of the prestigious science series Nova. This two-hour montage of interviews and reconstructions, to be shown on the Public Broadcasting Service (PBS) in the United States, features all the main players, bar one. Michael Behe, inventor of the specious meme "irreducible complexity" and guiding light of the intelligent-design movement, refused to participate. His testimony - the cornerstone of the defence - revealed a definition of science so loose that it includes astrology.

Herein lies the dramatic challenge of retelling this important story. The feebleness of the intelligent-design case, and the overwhelming strength of the prosecution in systematically deconstructing it, render the verdict clear just minutes into the programme. The makers of Judgement Day inject tension with eyewitness accounts from the people of Dover, and home-video footage of raucous school board meetings shows how passionate and divided this small community became. It works: it is inspiring to hear parents and educators, such as Sunday school and physics teacher Bryan Rehm, recount how they refused to be steam-rollered into bringing religion into the science classroom.

Judgment Day gracefully avoids ridiculing intelligent design for the pseudo-intellectual fundamentalist fig-leaf that it is, by simply showing how the protagonists shot themselves in the foot. They plead for the teaching of "alternative theories" to strengthen children's education (the misguided sentiment picked up by President Bush). But subpoenaed drafts of a textbook that promoted intelligent design reveal that the word 'creationists' was simply replaced with 'design proponents'. In one instance, this alteration was made so hastily it caused the misprint 'cdesign proponentsists', satirized by the prosecution as the transitional verbal fossil linking creationism to intelligent design.

At times in this overlong show, one feels almost sorry for the intelligent-design team, they're so inept. And then you remember that its champions take comments from scientists out of context and even lied under oath.
The judge at the centre of the dispute, John E. Jones III, is the hero of the piece. When this republican lutheran, appointed by the commander-in-chief himself, was assigned to the case, the pro-evolution lobby feared they had been dealt an unsympathetic ear. Happily, the measured, dry-witted Jones was fascinated by the comprehensive scientific case for darwinian evolution. He handed down a damning judgment that intelligent design is not science, and that its teaching is a violation of the cherished First Amendment. As a result, Time magazine rightly put him in their 2006 list of the world's 100 most influential people.

Intelligent design has not gone away. Next February, cinemas will be showing the prointelligent-design film Expelled: No Intelligence Allowed, written by comedian Ben Stein. Richard Dawkins, prominent anti-creationist blogger P. Z. Myers, and others claim the producers duped them into appearing.

But the Kitzmiller vs Dover verdict, matched this September with the outlawing of intelligent design in the UK national curriculum, marked the official neutering of this unpleasant, sneaky movement in much of the western world. Judgment Day is just the sort of thoughtful programming that celebrates how sensible people - faithful and otherwise - can use science and reason to combat fundamentalism.

Adam Rutherford is podcast producer for Nature.

For more information on the documentary, see www.pbs.org/wgbh/nova/id/

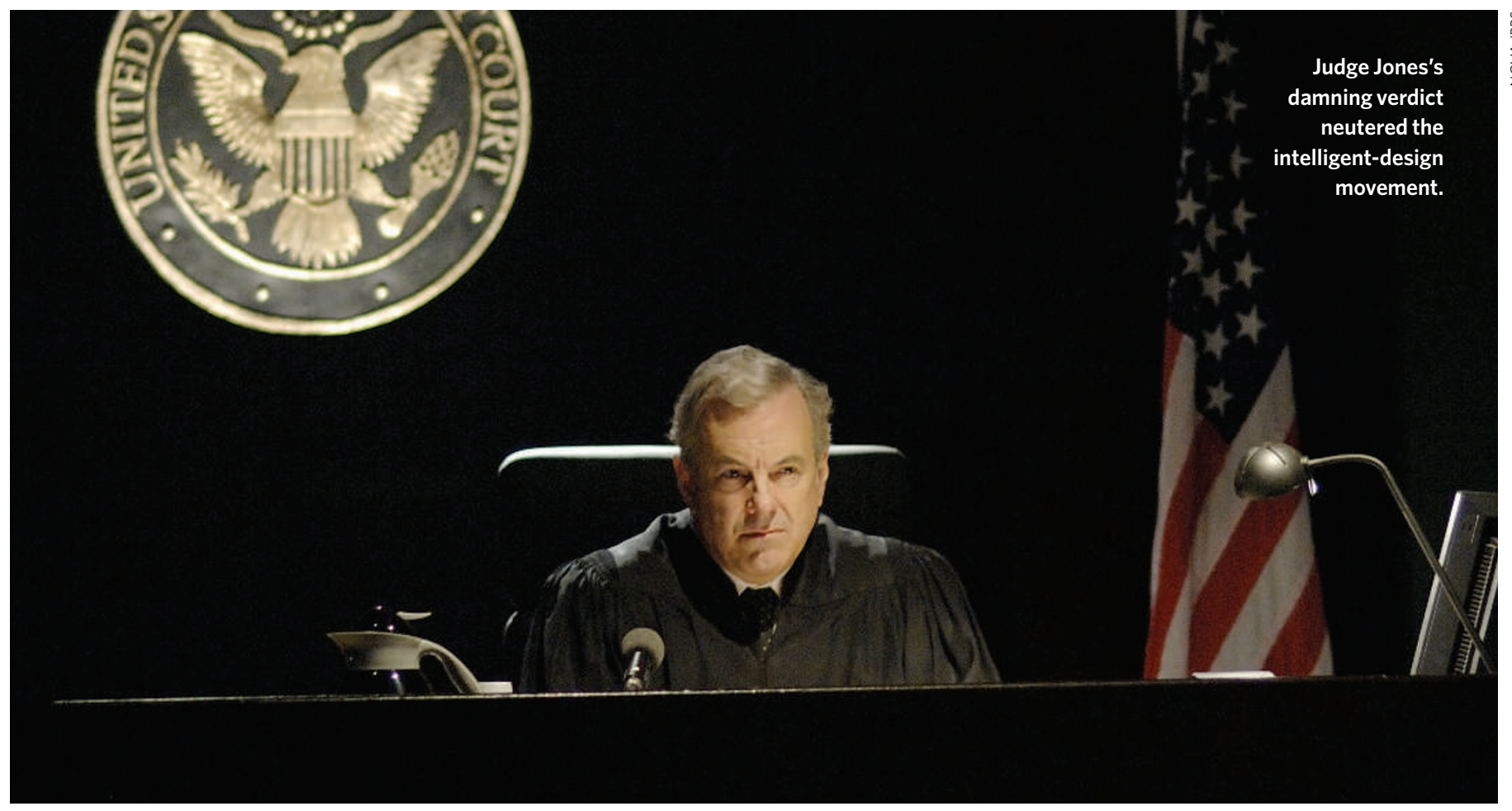

